\title{
The Relationship between Total Ige and Neutrophils Count with Degrees of Asthma Control in Adult Atopic Patients
}

\author{
Eko E Surachmanto ${ }^{1}$, Mochammad Hatta ${ }^{2, *}$, Andi Asadul Islam ${ }^{3}$, Syarifuddin Wahid ${ }^{4}$ \\ ${ }^{1}$ Department of Internal Medicine Faculty of Medicine, Sam Ratulangi University Manado, Indonesia \\ ${ }^{2}$ Molecular Biology and Immunology Laboratory, Faculty of Medicine, Hasanuddin University, Makassar, Indonesia \\ ${ }^{3}$ Department of Neurosurgery, Faculty of Medicine, Hasanuddin University, Makassar, Indonesia \\ ${ }^{4}$ Department of Pathology Anatomy, Faculty of Medicine, Hasanuddin University, Makassar, Indonesia \\ *Corresponding author: hattaram@yahoo.com
}

\begin{abstract}
Introduction: Asthma is a chronic reversible inflammation which is caused by bronchial hypereactivity due to exposure to allergen and hyperproduction of certain specific IgE. Neutrophil in respiratory tract and high level of IgE in the blood serum is known to play in complex mechanism in asthma development. The role of total IgE serum and neutrophil serum in asthma development is still not well known. Aim: This study aim is to assess the correlation between level of total IgE and neutrophil serum with degree of asthma control. Methods: This is a cross sectional study with 35 adult subjects with atophy asthma (age 22-61), all of participant reside in Manado and its surrounding area. Degree of asthma control is categorized as intermittent, mild persistent, moderate persistent and severe persistent based on criteria by GINA. Patient with malignancy, sepsis, lung tuberculosis, diabetes mellitus, pregnant, and late stage chronic kidney disease are excluded from this study. Result: In this study there is no significant correlation between total IgE serum level and degree of asthma control $(\mathrm{p}>0.05$.) also there is no significant correlation between each total IgE level and each degree of asthma control. There is significant positive correlation between neutrophil count and degree of asthma control $(r=0.309 ; \mathrm{p}<0.05)$. The higher neutrophil count is higher in mild persistent asthma in comparison with intermittent asthma is found to be significant $(\mathrm{p}<0.05)$. Conclusion: The neutrophil count in serum is related to degree of asthma control. Especially neutrophil count in mild persistent is higher than intermittent asthma. There is no correlation between total IgE level with degree of asthma control in adult subject with atopic asthma.
\end{abstract}

Keywords: atopic asthma, total Ig E, neutrophil count, degree of asthma control

Cite This Article: Eko E Surachmanto, Mochammad Hatta, Andi Asadul Islam, and Syarifuddin Wahid, "The Relationship between Total Ige and Neutrophils Count with Degrees of Asthma Control in Adult Atopic Patients." American Journal of Medical and Biological Research, vol. 6, no. 1 (2018): 7-10. doi: 10.12691/ajmbr-6-1-2.

\section{Introduction}

Asthma is disease which characterized by chronic inflammation of respiratory tract that is reversible. Patients of whom had history of allergy or atopy is categorized as people with atopic asthma. Degree of asthma control are categorized from mild to severe of which may influence the quality of life. [1] According to data from Center of Disease Control and Prevention (CDC) National Asthma Control Program in year 2010 there are 18,7 million of adult people live with asthma in the United States of America. [2] In Indonesia, the asthma prevalence is around 5-7\% from total citizens. Globally, prevalence rate of asthma in the world range from $7-10 \%$. Atopic asthma is account for $70-80 \%$ from total asthma patients. [3,4] The exposure to allergen will trigger the specific immunoglobulin E (IgE) in person with asthma and make inflammation reaction in bronchus. IgE is the main mediator in type 1 hypersensitivity, which play an important role as mediator in development and the degree of asthma control. It is still unknown whether the increasing production of local IgE play a role in degree of asthma control, the current knowledge is that allergen related IgE has more direct role in the exposure and trigger of asthma. [5,6]

Beside specific IgE as a well known mediator, neutrophils also thought to have a role in development of asthma in more complicated mechanism as a consequence of cytokines production and inflammation mediator. Neutrophils is generally found in respiratory tract using bronchoalveolar lavage (BAL) test in asthmatic patients especially in those with severe asthma, but the correlation between degree of asthma control and increasing amount of neutrophils in peripheral blood test is still unknown. ${ }^{7}$ This study purpose is getting to assess the correlation between total IgE and serum neutrophils toward the degrees of asthma control in adults atopic patients. The previous study has established the correlation between specific IgE-allergen and sputum neutrophils with degrees of asthma control, but none of the study has done to assess 
the correlation between the total IgE and neutrophils count in serum with degree of asthma control

\section{Methods}

\subsection{Study Population}

Population of this study consists of 35 adult subjects with atopic asthma (age 22 to 61 tahun). Participants are residents in Manado and the surrounding regions. All participants were questioned to obtain clinical and family histories, particularly histories of atopic syndrome and degree of asthma control. The degrees of asthma control are categorized in mild, intermittent, mild persistent, moderate persistent, and severe persistent according to the attacks in 1 week. Total IgE serum is measured with enzyme-linked immunosorbent assay (ELISA) methods, on the other hand the serum neutrophils count is obtained from the leucocyte in peripheral blood. In patients with malignancies, sepsis, lung tuberculosis, diabetes mellitus, pregnant women, late stage of chronic kidney disease (stage 4-5), and severe depression cannot be included in this study.

\subsection{Assessment of Clinical Data}

Asthma was diagnosed based on history, physical examination, and peak expiratory flow measurement according to Global Initiative for Asthma (GINA) guidelines. Atopy was determined by total serum IgE with result $\geq 120 \mathrm{IU} / \mathrm{ml}$, and/or by $\mathrm{SPT}$ with positive $\geq 1$ result toward housemite allergen. The degrees of asthma control are measured by the asthma attacks number, are categorized intermittent if no attack or seldom, mild persistent if there is $<2$ asthma attacks in a week, moderate persistent if the asthma attacks $\geq 2$ times in a week, and severe persistent if the asthma attacks persist everyday.

\subsection{Statistical Analysis}

This is a cross sectional study to study the correlation between total IgE and neutrophil counts for the degree of asthma control in adult patients with atopic asthma. The correlation between two variables was tested using the Pearson test if data distributed normally, or Spearman test if data not normally distributed. The variable difference total IgE and neutrophils count between severe degree asthma control group will be measured with ANOVA test and post hoc LSD. Distribution of data were tested using Klomogorov-Smirnov test.

\section{Result}

Demographic data and clinical characteristic of the study participants are shown in Table 1 . The average total IgE value and serum neutrophils in varying group of severe degree of asthma control can be seen in Table 2 .

\subsection{Relationship between Total IgE and Severe Degree Asthma Control}

Correlation between total IgE and severe degree asthma control are shown in Table 3. Spearman Test that we have done shows that there is no correlation between two variables ( $\mathrm{p}>0.05)$. In advanced analysis using anova posthoc LSD also shows that there is no significant result between Total IgE in every gorup of severe degree asthma control ( $p>0.05)$, as shown in Table 4.

\subsection{Correlation between Total IgE and Degree Asthma Control}

Correlation between total IgE and degree asthma control are shown in Table 5. Spearman test which has done shows that there is positive correlation between the two variables $(r=0.309)$ and statistically significant $(p<0.05)$. It shows that the higher neutrophils count, the degree of asthma control is worsen. In advanced analysis using anova post-hoc LSD comparison test there is a significant difference between neutrophils count in severe degree asthma control in intermittent and mild group $(\mathrm{p}<0.05)$, but there is no significant difference in mild to moderate group and moderate to severe. Difference analysis between severe degree asthma control group is shown in Table 6.

Table 1. Subject study characteristics

\begin{tabular}{ll}
\hline Variable $(\mathrm{n}=35)$ & \\
\hline Age, years (age \pm SD) & $43,14 \pm 11,58$ \\
Gender (number., \%) & $14(40 \%)$ \\
Female & $21(60 \%)$ \\
Male & $909,51 \pm 767,47$ \\
IgE total, IU/mL (average \pm SD) & $503 \pm 127,45$ \\
Neutrophils count, $/ \mathrm{mm}^{3}$ (average \pm SD) & \\
Severe degree asthma control (number., \%) & $6(17,1 \%)$ \\
Intermitent & $7(20 \%)$ \\
Mild & $12(34,3 \%)$ \\
Moderate & $10(28,6 \%)$ \\
Severe &
\end{tabular}

Table 2. Average value of Total IgE and neutrophils count in severe degree asthma control

\begin{tabular}{lccc}
\hline $\begin{array}{l}\text { Degree of asthma } \\
\text { control (Number, \%) }\end{array}$ & $\mathrm{N}$ & $\begin{array}{c}\text { IgE total, IU/mL } \\
\text { (average } \pm \mathrm{SD} \text { ) }\end{array}$ & $\begin{array}{c}\text { Neutrophils count, } \\
/ \mathrm{mm}^{3} \text { (average } \pm \text { SD) }\end{array}$ \\
\hline Intermittent & 6 & $792,67 \pm 642,45$ & $375,83 \pm 184,81$ \\
Mild & 7 & $825,57 \pm 702,57$ & $542,71 \pm 77,42$ \\
Moderate & 12 & $773,67 \pm 656,38$ & $493,58 \pm 113,02$ \\
Severe & 10 & $1201,40 \pm 1003,16$ & $562,80 \pm 81,79$ \\
\hline
\end{tabular}

Table 3. Correlation test between total IgE and severe degree asthma control

\begin{tabular}{lll}
\hline Variable $(\mathrm{n}=35)$ & $\mathrm{R}$ & $\mathrm{p}^{*}$ \\
\hline IgE total vs severe degree asthma control & 0,164 & 0,173 \\
\hline
\end{tabular}

* Spearman test.

Table 4. Anova post-hoc LSD test between total IgE and severe degree asthma control

\begin{tabular}{|c|c|c|c|c|}
\hline Total IgE \& severe degree asthma control & $\mathrm{p}^{*}$ & Mean Difference & Std. Error & 95\% Confidence Interval \\
\hline Intermittent vs mild & 0,940 & $-32,90$ & 433,50 & $-917,04--851,23$ \\
\hline Mild vs moderate & 0,890 & 51,90 & 370,58 & $-703,90-807,71$ \\
\hline Moderate vs severe & 0,209 & $-427,73$ & 333,63 & $-1108,18-252,71$ \\
\hline
\end{tabular}

* anova post hoc LSD test. 
Table 5. Correlation test between neutrophils count and degree of asthma control

\begin{tabular}{|c|c|c|c|c|}
\hline Variable $(n=35)$ & & & r & $\mathrm{p}^{*}$ \\
\hline neutrophils count vs degree of asthma control & & & 0,309 & 0,035 \\
\hline \multicolumn{5}{|l|}{ * Spearman test. } \\
\hline neutrophils count and severe degree asthma control & $\mathrm{p}^{*}$ & Mean Difference & Std. Error & 95\% Confidence Interval \\
\hline Intermittent vs mild & 0,014 & $-166,88$ & 63,78 & $-296,97--36,79$ \\
\hline Mild vs moderate & 0,375 & $-49,13$ & 54,52 & $-62,07-160,34$ \\
\hline Moderate vs severe & 0,168 & $-69,22$ & 49,09 & $-169,33-30,90$ \\
\hline
\end{tabular}

* anova post hoc LSD test.

\section{Discussion}

Asthma is an chronic inflammatory disease which makes abnormality in the airway system. Immunohistopathology pattern that is usually found are neutrophils, eosinophils, lymphocyte, mast cell, and damage in airway epithelial. The inflammation in the respiratory system and bronchoconstriction are being triggered as a hypersensitivity response to an exposure over allergens which is mediated by specific IgE. The bronchoconstriction mechanism is also can occur without IgE mediation, for example in asthma which is induced by aspirin and non steroid anti inflammation drugs (NSAIDs). Over activities, cold weather, and irritative substances also might be a stimuli to bronchial asthma $[8,9]$.

Atopic or alergic asthma is a subtype of asthma disease which based on familial atopic nature with elevation of total and specific immunoglobulin E (IgE) to inhalant allergens as the hallmark which is followed by mast cell degranulation. The most frequent inhalant allergens which can trigger the alergic reaction are house dust, pollen, and animals fur. A study by Manise et al. in year 2016 stated that there is a correlation between atopic asthma and the increased total IgE serum, especially in severe degree of asthma control. They also state that there is a correlation between demographic factor like age and gender with total IgE serum, whereas the aging and immunosenescence will reduce the total IgE level and men population have a tendency to higher total IgE. [10] Our study shows that there is no correlation between total IgE and degree of asthma control level, also there is no difference between total IgE level between every group. This could occur because of demographic factor in our varying subjects, and there is a possible variability between total IgE level like the result of a study held by Hatipoglu et al. on his asthma subjects with moderate, and severe alergies. [11] The hyperesponsive mechanism of the airway in asthma has a similar characteristic with allergic rhinitis, it is suspected that systemic IgE has a little role in comparison with local IgE. [12]

Neutrophils as inflammation mediator is shown by increasing number of neutrophil in airway and sputum from severe asthma subject. Its number can be varied because of corticosteroid use or bacterial infection. The relationship between neutrophils count in serum and the degree of asthma control is still unknown. [12] Molecularly, remodelling of extracellular matrix will occur in allergic asthma if the exposure to allergen is being mediated by matrix metalloproteinase-9 (MMP-9). Which according to a study by Ventura et all is produced by neutrophils and not by eosinophils. This depicts that neutrophils' role is not only in inflammation, but also in airway remodelling which affects the progressivity in severe degree of asthma control. [13] Our study shows a positive correlation between neutrophils count in serum and the degree of asthma control. The neutrophils count in patient with mild asthma in our study is higher than intermittent asthma.

There is no significant difference in neutrophils count in subject with mild, moderate, and severe asthma. This is relevant with the previous study whereas neutrophils also have role toward severe degree of asthma by activation of $\mathrm{T}$ helper cell (Th) 2 dan Th17. The novel therapy antineutrophil and monoclonal antibody is still under development but still futile clinically in uncontrolled asthma subject. [14,15] According to the study of VedelKrogh et al, asthma subjects with high neutrophils count in serum are mostly using inhalant corticosteroid. It is presumed that the high neutrophils count is due to delayed apoptosis from corticosteroid's effect. But overall, neutrophils count in serum can reflect the inflammation of airway and give us easier methods in examining biomarker in severe degree of asthma control. [16]

\section{Conclusion}

The neutrophils count in serum is related to the degree of asthma control. In our study, the neutrophils count in mild asthma group is higher than intermittent asthma. Other variables in our study is total IgE serum is not related to the degree of asthma control in adult atopic asthma subject. The mechanism and pathophysiology of the increased neutrophils count in more severe asthma control group still need further study.

\section{Acknowledgments}

None.

\section{Declarations}

\section{Funding}

Funding for this study was done by the author. No conflict of interest nor sponsorship was reported in this study. 


\section{Conflict of Interests}

The authors declare that there is no conflict of interests regarding the publication of this paper.

\section{Ethical Approval}

This study was approved by the Institutional Research Board of Prof. Dr. R. D. Kandou Manado Hospital, Indonesia (Approval PP 38/IV/Dik/2015). Patients gave written informed consent about this study.

\section{References}

[1] Global Initiative for Asthma. Global strategy for asthma management and prevention. 2015.

http://ginasthma.org/wpcontent/uploads/2016/01/GINA_Pocket_2015.pdf.

[2] Centers for Disease Control and Prevention. Data from the CDC National Asthma Control Program 2012 [Internet]. Atlanta, GA 20155 Oct - [cited 2015 Oct 6]. Available from:

http://www.cdc.gov/asthma/pdfs/investment_americas_health.pdf.

[3] Sundaru H, Sukamto. Asma bronkial. In: Sudoyo AW, Setiyohadi B, Alwi I, Simadibrata M, Setiati S. ed. Buku Ajar Ilmu Penyakit Dalam edisi ke 5. Jakarta: Internal Publishing; 2009.

[4] Lazarus S. Emergency Treatment of Asthma. N Eng J Med 2010; 363: 755-64.

[5] Oettgen HC, Geha RS. IgE regulation and roles in asthma pathogenesis. J allergy Clin Immunol 2001; 107: 429-40.

[6] Froidure S, Mouthuy J, Durham SR, Chanez P, Sibille Y, dan Pilette C. Asthma phenotypes and IgE responses. Eur Respir J 2015.
[7] Ciepiela O, Ostafin M, Demkow U. Neutophils in asthma- A review. Respir. Physiol. Neurobiol (2014), http://dx.doi.org/10.1016/j.resp.2014.12.004

[8] Griitendorst DC, Rabe KF. Mechanism of bronchial hyperactivity in asthma and chronic obstructive pulmonary disease. Proc Am Thorac Soc 2004; 1: 77-87.

[9] Nadel JA, Busse WW. Asthma. Am J Respir Crit Care Med 1998; 157: 130-38.

[10] Manise M, Bakayoko B, Schleich F, Corhay JL, Louis R. IgE mediated sensitisation to aeroallergens in an ashmatic cohort: relationship with inflammatory phenotypes and disease severity. Int J Clin Pract 2016; 70(7): 596-605.

[11] Hatipoglu U, Subramanian A, Campbell T, Rice R, Mummadi S, $\mathrm{Hu} \mathrm{B}$ and Lang D. Intrasubject variability in total IgE levels in patients with moderate to severe allergic asthma over 1 year. J Allergy Clin Immunol Pract 2016; 4(4): 691-6.

[12] Barnes PJ. Asthma mechanism. Medicine 2016, http://dx.doi.org/10.1016/j.mpmed.2016.02.020.

[13] Ventura I, Vega A, Chacon P, Chamorro C, Aroca R, Gomez E, et al. Neutrophils from allergic asthmatic patients produce and release metalloproteinase- 9 upon direct exposure to allergens. Allergy 2014; 69: 989-905.

[14] Pelaia G, Vatrella A, Busceti MT, Gallelli L, Calabrese C, Terracciano R, et al. Cellular mechanism underlying eosinophilic and neutrophilic airway inflammation in asthma. Mediators of Inflammation 2015.

[15] Busse WW, Holgate S, Kerwin E. Randomized, double blind, placebo-controlled study of brodalumab, a human anti-IL-17 receptor monoclonal antibody, in moderate to severe asthma. The American Journal of Respiratory and Critical Medicine 2013; 188(11): 1294-1302.

[16] Vedel-Krogh S, Nielsen SF, Lange P, Vestbo J and Nordestgaard BG. Association of blood eosniphil and blood neutrophil counts with asthma exacerbations in the Copenhagen general population study. Clinical Chemistry 2017; 63(4): 823-32. 